\title{
Modeling 3D Scanned Data to Visualize the Built Environment
}

\author{
Yusuf Arayici, Andy Hamilton \\ The University of Salford, Greater Manchester \\ \{a.hamilton@salford.ac.uk, y.arayici@salford.ac.uk\}
}

\begin{abstract}
Capturing and modeling $3 D$ information of the built environment is a big challenge. A number of techniques and technologies are now in use. These include EDM, GPS and photogrammetric application and also remote sensing applications. In this paper, we discussed $3 D$ laser scanning technology, which can acquire high density point data in a accurate, fast way. Therefore, it can provide benefits for refurbishment process in the built environment.

The scanner can digitize all the $3 D$ information concerned with a building down to millimetre detail. A series of scans externally and internally allows an accurate $3 D$ model of the building to be produced. This model can be "sliced" through different planes to produce accurate $2 D$ plans and elevations. This novel technology improves the efficiency and quality of construction projects, such as maintenance of buildings or group of buildings that are going to be renovated for new services.

Although data capture is more efficient using laser scanner than most other techniques, data modeling still presents significant research problems. These are addressed in this paper.

The paper describes the research undertaken in the EU funded (FP6 IP) INTELCITIES project concerning $3 D$ laser scanner technology for CAD modeling and its integration with various systems such as $3 D$ printing and VR projection systems. It also considers research to be undertaken in the EU funded (INTERREG) Virtual Environmental Planning Systems (VEPS) project in the next 2 years. Following this, an approach for data modeling of scanned data is introduced, through which the information belonging to existing buildings can be stored in a database to use in building, urban, and regional scale models.
\end{abstract}

Keywords- Laser scanner, data modeling, visualization, built environment, integration, objects recognition.

\section{Introduction}

Terrestrial laser scanning is the use of a ground based device that uses a laser to measure the three dimensional coordinates of a given region of an objects surface automatically, in a systematic order at a high rate in near real time. It is also referred to as close range laser scanning [1].

The scanner is targeted to the physical objects to be scanned and the laser beam is directed over the object in a closely spaced grid of points. By measuring the time of laser flight, which is the time of travel of the laser from the scanner to the physical objects and back to the scanner, the position in three-dimensional space of each scanned point on the object is established. The result is a "cloud of points" which consists in thousands of points in 3-dimensional space that are a dimensionally accurate representation of the existing object [2]. This information can then be converted in a 3D CAD model that can be manipulated using CAD software, and to which the design of new equipment can be added.

This innovation is significant because it has potential to solve the problems that are always been associated with design and construction of existing buildings for reuse goals [10]. For example, it can provide faster, better quality and more precise analysis and feature detection for building survey. The advantages and disadvantages of this technology is shown in the below table [6]. 3D laser scanning technology advantages and disadvantages are summarized in Table 1.

In the built environment, the use of the 3D laser scanner enables digital documentation of buildings, sites and physical objects for reconstruction and restoration. It also enables the creation of educational resources within the built environment including cultural heritage. Furthermore, it can provide reverse engineering in construction for the reuse of the existing buildings. Producing building design and CAD models and VR models from an existing building by means of the laser scanner will facilitate the communication between the stakeholders through 3D visualization and facilitate the analysis of the latest conditions of the buildings. Besides, it has also potential to 
accurately record inaccessible and potentially hazardous areas. Consequently, it facilitates "virtual refurbishment" of the buildings and allows the existing structure and proposed new services to be seen in an effective manner [9]. The potential of $3 \mathrm{D}$ scanners need to be matched against current cost and other limitations noted in the table above.

\begin{tabular}{l|l}
\hline \multicolumn{2}{c}{ 3D Laser Scanning } \\
\hline $\begin{array}{l}\text { Advantages } \\
\text { Applicable to all 2D } \\
\text { and 3D surfaces }\end{array}$ & $\begin{array}{l}\text { Some systems do not } \\
\text { work in sun or rain }\end{array}$ \\
\hline $\begin{array}{l}\text { Rapid 3D data } \\
\text { collection-near real } \\
\text { time }\end{array}$ & $\begin{array}{l}\text { 3D data sets needs post- } \\
\text { processing for a useable } \\
\text { output }\end{array}$ \\
\hline $\begin{array}{l}\text { Very effective due to } \\
\text { data collected at a a } \\
\text { predictable precision }\end{array}$ & $\begin{array}{l}\text { Difficulty in extracting } \\
\text { the edges from } \\
\text { indistinct data clouds }\end{array}$ \\
\hline $\begin{array}{l}\text { Ideal for 3D modeling } \\
\text { and visualization } \\
\text { purposes }\end{array}$ & $\begin{array}{l}\text { Output } \\
\text { manipulation for good } \\
\text { recording quality }\end{array}$ \\
\hline $\begin{array}{l}\text { Both 3D position and } \\
\text { surface reflectance can } \\
\text { be viewed as an image }\end{array}$ & $\begin{array}{l}\text { No common data } \\
\text { exchange format in use } \\
\text { for third parts }\end{array}$ \\
\hline Rapidly developing & $\begin{array}{l}\text { Difficult to stay up-to- } \\
\text { date with developments }\end{array}$ \\
survey technology & Table 1: Advantages and disadvantages of
\end{tabular}

\section{Table 1: Advantages and disadvantages of 3D laser scanning technology}

\section{The Intelcities Project}

The INTELCITIES (Intelligent Cities) Project is a research and development project that aims at helping achieve the EU policy goal of the knowledge society. INTECLITIES project brings together the combined experience and expertise of key players from across Europe, focusing on eGovernment, e-Planning and e-Inclusion, e-Land Use Information Management, e-Regeneration, Integration and Interoperability, Virtual Urban Planning, etc, (www.intelcitiesproject.com).

The overall aim is to advance the possibilities of eGovernance of cities to a new level through the development of a prototype of the IOSCP (Integrated Open System City Platform), as a clear and easily accessible illustration of a shared civic place in virtual space continuously available to all - whether officials, decision-makers and other professionals, such as planners, developers, politicians, designers, engineers, transport and utility service providers, as well as individual citizens, community groups/networks and businesses, through a wide range of interfaces This paper focuses on the e-Regeneration work package in which there are two main tasks identified for the use of laser scanner technology [6]. These are as follows:
The building data capture: Capture of digital data of existing buildings using 3D laser scanning equipment. Show how this data can be used as an information base to enhance the refurbishment process.

$>$ Building data integration: Build concept $\mathrm{nD}$ modelling system and relate to other data structures including relational databases to illustrate how data can be integrated to support intelligent city systems.

The rest of the paper elaborates the research on building data capture and integration and data modeling concept for the scanned data in the Intelcities project.

\section{Visualization of 3D Models}

The main purpose of building data modeling is to help in thinking about real world problems. Advanced digital mapping technologies such as 3D laser scanners and 3D printing can be enablers for effective e-planning, consultation and communication of users' views during the planning, design, construction and lifecycle process of built and human environments. The regeneration and transformation of cities from the industrial age (unsustainable) to the knowledge age (potentially sustainable) is essentially a 'whole life cycle' process consisting of; planning, development, operation, reuse and renewal. In order to enhance the implementation of build and human environment solutions during the regeneration and transformation of cities, advanced digital applications can have a significant impact.

Figure 1 illustrates the concept of the use of the laser scanner technology in integration with other tools for visualization.

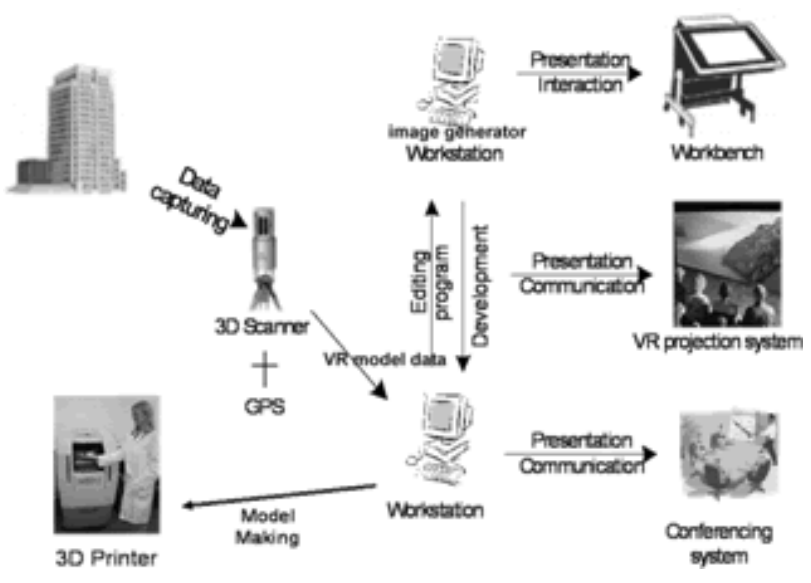

Figure 1: Integration of spatial data with 3D printed and the virtual environments

Within the built environment, the use of the 3D laser scanner enables digital documentation of buildings, sites and landscapes for reconstruction 
and restoration. Besides, technologies such as 3D printing allows for the creating of plastic models from the digital record to. The use of the 3D scanner in combination with the 3D printer provides the transformation of digital data from the captured CAD model back to a physical model at an appropriate scale - reverse prototyping. The use of these technologies is a key enabler in the creation of an integrated system to capture, process, and display $3 \mathrm{D}$ information.

The laser scanner can provide reverse engineering in construction for the reuse of the existing facilities. Producing CAD and VR models from existing buildings, by means of the laser scanner, will facilitate an analysis of the latest conditions of the buildings. They even have the potential to accurately record inaccessible and potentially hazardous areas such as pitched rooftops. Consequently, it facilitates "virtual refurbishment" of the buildings and allows the existing structure and proposed new services to be seen in an effective manner. Figure 2, 3 and 4 shows the Jactin House example, which is the case study building in East Manchester, for VR models produced from the building data captured by the $3 \mathrm{D}$ Laser scanner and CAD models extracted from the VR models.

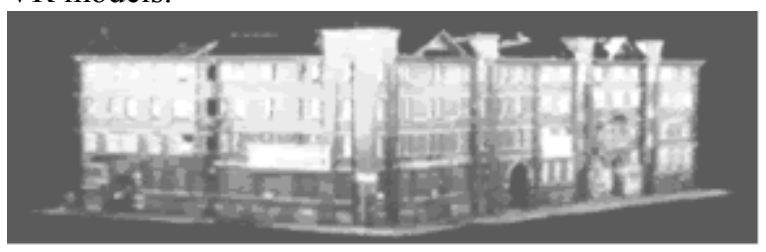

Figure 2: Jactin House exterior model

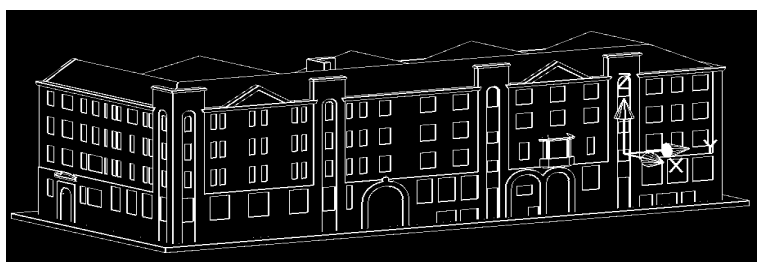

Figure 3: Jactin House CAD model

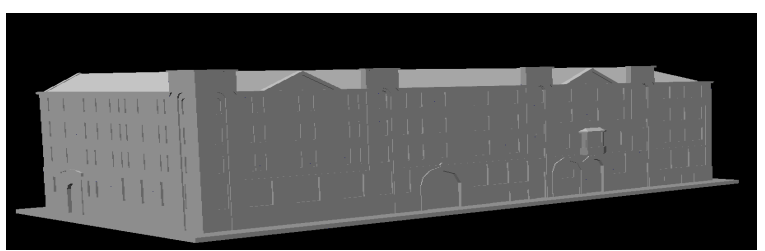

Figure 4: Printed model of Jactin house

This innovation is significant because it has potential to solve the problems that are always been associated with design and construction of existing buildings for reuse. For example, it can provide faster, better quality and more precise analysis and feature detection for building surveys.

For instance, in regard to cultural heritage sites, many historical buildings are slowly deteriorating due to exposure to the elements. Although remediation efforts can reduce the rate of destruction, a digital model of the site will preserve accurate 3D information about the site indefinitely. Models of historical artefacts also allow scientists to study the objects in new ways. For example, archaeologists can measure artefacts in non contact fashion, which is useful for fragile objects. Also digital models allow objects to be studied remotely, saving time and travel expenses and enabling more archaeologists to study them.

In regard to civil engineering, modelling from reality offers an efficient alternative to surveying. For example, bridges need to be surveyed periodically to determine whether significant settling or other movement has occurred. A 3D model of the site allows engineers to make the same measurements with equivalent accuracy in a fraction of the time.

With regard to reverse and rapid prototyping, modelling from reality can be used to reverse engineer manufactured parts for which a CAD model is unavailable or never existed. Modelling from reality "imports" the prototype into a computer, creating a digital model that can be edited with a CAD program.

Regarding architecture and construction, architects frequently need to determine the "as built" plans of building or other structures such as industrial plants, bridges, and tunnels. A 3D model of a site can be used to verify that it was constructed according to specifications. When preparing for a renovation or a plant upgrade, the original architectural plans might be inaccurate, if they exist at all. A 3D model allows architect to plan a renovation and to test out various construction options.

The Integrated visualisation environment described in figure 1 is developed to use laser scanner technology to provide data models in different formats including the Virtual Reality Modelling Language (VRML). Figure 5 below shows demonstration of peel building in the VR projection system as an example of a VR environment, which has been implemented at the University of Salford.

The research has practical applications in the construction industry and related professions. It will provide a better support for evaluation and visualisation of building maintenance works so that informed policies can be effectively targeted. It will benefit construction companies, facility and estate managers, and all those concerned with building maintenance issues [10]

To make the information flow as the arrows illustrate in figure 1 several problems need to be overcome. One basic problem is the nature of scanned $3 \mathrm{D}$ data. Whereas $2 \mathrm{D}$ data captured by a camera confirms to accepted data standards (JPEG, 
TIFF, etc.) current 3D data output varies in format from scanner to scanner. This data conversion issue is discussed in the next section.

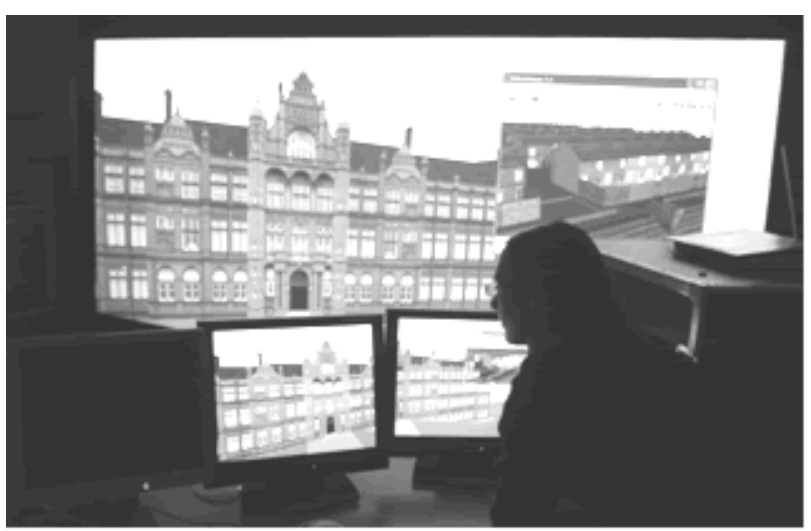

Figure 5: Peel building data capture by laser scanner is presented in VR Projection System

\section{The VEPS Project}

The Virtual Environmental Planning System (VEPS) project is an INTERREG IIIB funded project undertaken by a European Consortium in North-West Europe. The first phase of the project started in December 2004. The goal of the project is to share technical advantages in $3 \mathrm{D}$ visualization, ICT (Information and Communication Technologies) applications to promote public consultation; environmental modeling, data collection and use for e-planning in territorial development in North-West Europe. The current planning systems for decision making is based on 2D data and information, which is inadequate for the communication between stakeholders who are coming from different background and disciplines. This can result in interpretation and misjudgment during the decision making of environmental planning. Instead, forming a intuitive virtual environmental planning system, which can manipulate $3 \mathrm{D}$ data and information, will improve the efficiency and productivity in decision making process of environmental planning. Besides, providing intuitive visualization system can help the public participation in the decision making process of environmental planning.

Therefore, in the VEPS project, it is aimed at developing a common architecture and methodology to enable public people to view and respond to planned changes via standard PCs. The key activity in the VEPS project is analysis of large data sets, including high resolution 3 dimensional height data from LIDAR, for use within Virtual Reality (VR) visualization software and the subsequent delivery of the VR environment via the Internet and World Wide Web. The virtual environments used in VEPS can look extremely realistic as the Lidar images demonstrate.

Through the VEPS project, the research on laser scanner technology moves on the urban and regional scale while the research has been carried out at the building and urban scale in the Intelcities project. In other words, the issues of building data capture and building data integration, which are addressed in section 2 , will be considered at a larger scale through investigating data standardization, modeling and integration with other VR systems.

The following section introduces a research angle of object recognition for the modeling of laser scanned data for standardization and for visualization at building scale and at urban scale. As a result, the issues in the Intelcities project and in the VEPS project will be covered.

\section{Object Recognition Approach for Data Modeling}

To make progress in the area of modeling, conversion issues of $3 \mathrm{D}$ scanned data need to be solved. The general problems of $3 \mathrm{D}$ data integration in the built environment are considered elsewhere [10]. In this section we specifically address the problem of object recognition. This is important in realizing the visualization of $3 \mathrm{D}$ models of the built environment because visualization will be undertaken with the real characteristics and features of the real world objects as opposed to raw 3D models of laser scanned data, which is difficult to handle by many visualization software applications due to big file sizes. As a result data modeling and analysis of laser scanned data can also be done more effectively and precisely. It also facilities the use of CAD and GIS software which will not normally support raw scanned 3D models..

There are certain barriers; for example; there are no standard formats for the distribution of scanned data. This leads to issues relating to compatibility, exchange of information and data archiving. These barriers can be overcome through data conversion from scanned data to a standard data formats such as IFC (www.iai.org.uk) or IFG (Industry Foundation Classes for GIS). IFC is an international data standard model for information sharing and interoperability in the construction industry. On the other hand, IFG also makes it possible to communicate relevant intelligent information from various GIS standards to CAD systems using IFC [10].

In the Intelcities research programme, we have an approach for object recognition through simultaneous recognition of multiple objects in scenes of polygonal mesh models produced from the laser scanner point cloud data, which contains 
clutter and occlusion. Recognition is based on matching surfaces by matching points using spin image representation. Spin image is a data level descriptor that is used to match surfaces represented as a surface mesh [3]. The diagram below that describes the process of object recognition from the laser scan data is developed based on spin image definition from [3], [4], [5].

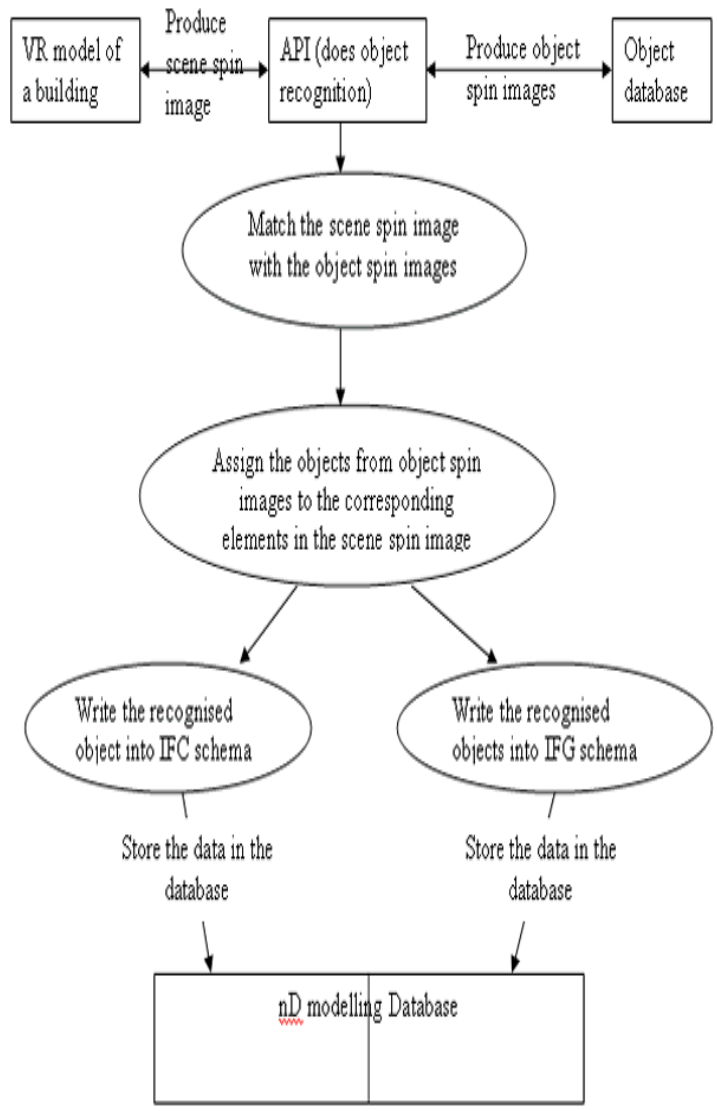

Figure 6: the process of object recognition from a building VR model developed from the laser scanner system

Through surface matching, an object can be identified in a scene of laser scanned data by comparing a targeted surface to an object surface stored in a database. When the object surface is matched, an interrelation can be established between something known (the object) and something unknown (the scene of laser scanned data). As a result, information about the world is acquired.

Surface matching is based on matching individual surface points in order to match complete surfaces [3]. By matching points, the problem of surface matching is broken down into many smaller localized problems of point matching. As a result, matching points provides a method for handling clutter and occlusion in surface matching without first segmenting the scene; clutter points on one surface will not have matching points on the other, and occluded points on one surface will not be sought on the other [11].

To differentiate among points, 2D images associated with each point are constructed. Oriented points, which are $3 \mathrm{D}$ points with associated directions, are used to create spin images. An oriented point is defined at a surface mesh vertex using the 3D position of the vertex and surface normal at the vertex. The surface normal at a vertex is computed by fitting a plane to the points connected to the vertex by edges in the surface mesh (see [4] and [5] for spin image creation in detail).

According to the diagram in figure 6, polygonal model mesh is invoked by the API (Application Programming Interface) to be developed in order to create scene spin image based on a selected scene oriented point. At the same time, the system will access the object database to create spin images for each object model in the database and these spin images are stored in a spin image stack. Point correspondences are then established between the selected point and the points with best matching spin images on the other surface. This procedure is repeated for many points until sizeable set point correspondences. Point correspondences are then grouped and outliers are eliminated using geometric consistency.

This surface matching can be extended to object recognition as follows. Each object in the object database is represented as a polygonal mesh. Before recognition, the spin images for all vertices on all models are created and stored. At recognition time, a scene point is selected and its spin image is generated. Next, its spin image is correlated with all of the spin images from all of the objects. The best matching model spin image will indicate both the best matching model and model vertex. After matching many scene spin images to model spin images. The result is simultaneous recognition and localization of the objects that exist in the scene [12].

The following step is to assign and populate objects to the corresponding elements in the scene of the laser scanner VR mesh model. In the end, new VR model is an object-populated mesh model. The following step is to write these objects in the scene into the IFC schema at building scale or IFG schema at city scale [8]. IFC enabled CAD software assists the professionals when planning a building or an area with buildings by supplying attribute information type of window, cost \& performance) directly connected to the $3 \mathrm{D}$ model. For larger scale integrated data it is also necessary to extract parts of the site and building information (in IFC form) and make it available in GIS standards. 
The information characterised by either IFC schema or IFG schema will be stored in the $\mathrm{nD}$ modelling [7] database. $\mathrm{nD}$ modelling database is a multi dimensional data storey to keep information for various systems at building scale and urban scale.

This is ongoing progress and the focus of the future work will be the algorithm definition for object recognition for data conversion from scanned data to $\mathrm{nD}$ modelled data

\section{Conclusions}

The paper explained the research on the use of laser scanner technology for built environment. The focus was the e-regeneration to facilitate the building refurbishment process. Therefore, building data capture by laser scanner and building data integration with various systems are addressed.

In the paper, the research projects such as the intelcities and VEPS projects were introduced and their scope for the use of the laser scanner technology for the built environment at building scale and urban scale was described. The research undertaken in these projects about 3D laser scanner technology mainly focus on the data capture and modeling. Case studies of Jactin House and Peel building were given as examples for CAD and VR modeling and integration with other technologies such 3D printer and VR projection system. Furthermore, potential benefits of using 3D laser scanner were addressed. Lastly, an approach of object recognition for object-oriented data modeling from the 3D scanned data was discussed. The benefits of this approach were noted. For example, providing information in a standard formats such as IFC and IFG about the built environment using the laser scanner through object recognition approach will enable to communicate with other city and building systems including CAD and GIS systems.

Although present use is quite labor and time intensive, it is envisaged that when the data conversion problems are solved, use of laser scanner VR models can be developed quickly, which will make it feasible for intelligent visualizations to be produced for a wide range of applications. Some of these applications will be explored in the VEPS project.

\section{Acknowledgements}

The project work presented in this paper is cofinanced through the INTERREG IIIB North West Europe programme.

\section{References}

[1] Bryan, P., (2003), An Addendum to the Metric Survey Specifications for English Heritage, The Metric Survey Team, YORK.

[2] Schofield, W., (2001) "Engineering Surveying 5th Edition: Theory and Examination Problems for Students".

[3] Johnson, A.E., Hebert, M., "Using Spin Images for Efficient Object Recognition in Cluttered 3D Scenes", IEEE Transaction on Pattern Analysis and Machine Intelligence, Vol 21, NO 5, May 1999.

[4] Johnson A.E., and Hebert, M., "Surface Matching for Object Recognition in Complex Three-Dimensional Scenes," Image and Vision Computing, vol. 16, pp. 635-651, 1998.

[5] Johnson, A.E., Spin-Images: A Representation for 3-D Surface Matching, doctoral dissertation, The Robotics Institute, Carnegie Mellon Univ., 1997.

[6] Arayici, Y., Hamilton, A., Gamito, P., Albergaria, G., (2004) The Scope in the INTELCITIES Project for the Use of the 3D Laser Scanner, in the Proceeding of ECT2004: The Fourth International Conference on Engineering Computational Technology, 7-9 September 2004, Lisbon, Portugal. ISBN 0948749962

[7] Lee, A. Marshall-Ponting, A.J. Aouad, G. Wu, S. Koh, W. W. I. Fu, C. Cooper, R. Betts, M. Kagioglou, M. and Fisher, M (2003). Developing a vision of nD-enabled construction, Construct IT, University of Salford, UK

[8] Wang, H., Hamilton, A. (2005). Data integration issues within $\mathrm{nD}$ Information Modelling for Urban Planning. 5th International Postgraduate Research Conference, Salford, UK, Blackwell Publishing P194-203

[9] Ahmed V., Arayici, Y., Hamilton, A., Aouad, G., (2004), Virtual Building Maintenance: Enhancing Building Maintanance Using 3DGIS and 3D Laser Scanner (VR) Technology, the Proceeding of European Conference o Product and Process Modelling in the Building and Construction Industry (ECPPM), 8-10 September 2004, Istanbul, Turkey ISBN 04 15359384 pp 29-34

[10] Arayici, Y., Hamilton, A., (2005), "Built Environment Reverse and Forward Prototyping", International SCRI Symposium, University of Salford, Greater Manchester, $12^{\text {th }}$ $-13^{\text {th }}$ April 2005.

[11] Ullman, S., Vidal-Naguet, M., and Sali, E., "Visual features of intermediate complexity and their use in classification", Nature Neuroscience, 5(7): 682-687, July 2002.

[12] Stein, A., Hebert, M., "Incorporating Background invariance into Feature-Based Object Recognition, $7^{\text {th }}$ IEEE Workshop on Application of Computer Vision, January 2005 